\title{
The Garden Landscape Design Research Based on Regional Culture
}

\author{
Xiang Pan \\ Sichuan Agricultural University, China
}

Keywords: Regional, regional culture, garden, landscape design

\begin{abstract}
Design is the main means of the connotation of the landscape design. When designing, it is necessary to give full consideration to the artificial factors and natural elements to meet people's needs in social life, ecological environment, cultural life and other aspects, and to enrich people's spirit and material life. The garden landscape is designed to give people a comfortable living environment and improve their quality of life. Therefore, in the landscape design, the local geographical culture should be subtly integrated into the landscape. This paper analyzes the relationship between landscape design and regional culture and the characteristics of regional culture in landscape design.
\end{abstract}

\section{Introduction}

With the development of economic integration and globalization, the differences in urban garden landscapes are gradually narrowing. We need cities with strong regional characteristics and cultural connotations. We will use landscape culture as the background and theme to create garden landscapes. The combination of regional culture and garden landscape can create a new urban garden culture. For this reason, through the excavation of Fenghua's regional culture, this paper integrates the diversity of the regional culture into the landscape design, and promotes the development of Fenghua's characteristic landscape.

\section{Overview of Regional Culture and Landscape}

\subsection{Regional Culture}

Generally speaking, it refers to the entire material and spiritual achievements and achievements that have been created and continuously accumulated, developed and sublimated through mental labor and physical labor within a certain area of mankind through long-term historical development. It is a reflection of the natural environment of the region itself, which reflects the human use and transformation of nature. It is not only the result of a combination of various natural factors and human factors within a certain geographical range, but also the history of the region formed and perceived by people [1]. And the various cultural phenomena identified and related to the local values, economic levels, scientific and technological achievements, cultural accomplishments, religious beliefs, artistic standards, lifestyle, social customs, social behavior standards and other aspects.

Regional culture generally includes three interrelated levels: one is the natural level, the second is the humanistic level, and the third is the social level. The natural level is mainly composed of landforms, topography, plants, water bodies, climate conditions and other elements that affect the formation and development of regional culture; the humanities level includes historical traditions, conceptual customs, customs, etc. in a certain landscape environment [1]. The level mainly includes the social organization system and economic development status in a specific geographical environment.

\subsection{Landscape}

Garden landscape is a process in which visual matters or events are combined and expressed in a specific four-dimensional space-time continuum so that the form, imagery, and meaning of the landscape can be effectively presented. At the formal level, the landscape design should give the object a certain external form, such as a specific shape, size, color, texture, etc., to reflect the surface 
properties of the landscape; at the image level, it must be organized through the spatial structure and the necessary symbolization process makes the landscape show corresponding connotations, such as the characteristics of the place and the nature of the environment [2]. At the level of meaning, it is given by integrating the symbolic factors such as local history, culture, and life into the specific landscape design. The landscape has a deeper cultural connotation.

\subsection{The Development of Regional Culture in Landscape Design}

Regional culture not only witnessed the development of history, but also the crystallization of human spiritual civilization. At this stage, modern civilization has brought great impact on regional culture and brought new opportunities for development. New ways of thinking and concepts allow people to think about regional culture from multiple perspectives. Regional culture also has more diverse choices in the way of development and dissemination. Factors such as science and technology, culture, nature, and economy also mutually reinforce each other, and landscape architects need to find a balance point for regional culture in this seemingly contradictory situation [2]. From the local reality, they are designed to meet the needs of the broad masses of the people. Garden works. The design concept of the landscape is the key factor in determining the success of the design. The most important point in the design concept is the principle of humanization. The humanity of the design means that the designer respects the local culture and reflects the people-oriented design concept. The development pattern of culture will inevitably be diversified and will not converge. People-oriented should also be the primary principle of landscape design, and the regional culture is bound to return to the landscape design.

Different geographic environments between regions can form different regional cultures. This is the so-called "one side water and soil conservation." Regional cultural features and natural features are two major factors that influence the generation of regional culture. Among them, natural features refer to the complexes that constitute the means of production in human society. This is the basis for human development and survival [2]. The natural features mainly include the hydrological conditions and climatic conditions of a certain region. People living in a certain environment for a long period of time will be constrained and affected by such natural factors as the soil environment, geological features, and flora and fauna. Different natural characteristics will lead to different lifestyles, which will in turn affect the formation of regional values, religious beliefs, and so on.

In the local culture, people are creators. The fundamental reason for the creation of regional culture is that human beings have different behaviors in order to adapt to different natural environments. It is because of the existence of different regional cultures around the world that the world will be more colorful. Since the day of its creation, regional culture has gradually developed and improved with the evolution of history and the passage of time [1]. In the process of development and improvement, regional culture will remove cultural factors that are not conducive to its own development, absorb external factors conducive to its own development, and further improve its own cultural heritage. The characteristics of regional culture in its development mainly include historical inheritance, morphological stability, and cultural uniqueness. It takes a relatively long period of time for its formation and a relatively stable social nature and environment.

\section{The relationship between regional culture and landscape}

\subsection{Regional culture is the source of landscape design}

Garden landscape design is a discipline based on humanities, arts and natural sciences. The methods and objects of the landscape design will change with different regions. The regional culture can provide a large amount of material for the landscape design, so that the design fully reflects the local culture, customs, historical context and customs. Only after conducting a profound study of the regional culture and exploring, understanding and absorbing the regional culture on the basis of this, the designer can better reflect the regional cultural connotation when designing the landscape [3]. When designing garden landscapes, only a deep understanding of the development of regional culture and the process of production, understanding of the interaction between the natural environment and 
human beings, and then designing in light of actual conditions can fully interpret design concepts in design. Designers of landscape architecture are looking for design inspiration and materials from the elements that make up a regional culture.

\subsection{Landscape design and regional culture complement each other}

The ultimate form of landscape design is the actual landscape. This expressive force provides a broad space for the development and reproduction of regional culture. Cultural concepts in the regional culture and the essence of people's lives can be expressed through it [4]. Designers must organically combine regional culture with modern cultural concepts, blend historicity with modernity, and allow visitors to appreciate the history, taste, culture, and essence of the times. The shape is the existence of regional culture in the form of state of matter. Its concrete form and form are condensed in the landscape design.

\subsection{The Significance of Regional Culture in Landscape Design}

The modern city image tends to be more unified and has no geographical features. The garden landscape in the city also lost its color. Adding regional cultural characteristics in landscape design can promote the construction of featured cities. With the rapid development of modern civilization, traditional culture is gradually fading with the passage of time [3]. Adding regional cultural characteristics in landscape design can dig out the cultural essence of the region, integrate modern architecture with historical culture, integrate historical culture with modern culture, and ultimately allow traditional culture to inherit and develop in this fusion. Progress will give new life to traditional culture.

\section{The Application of Regional Culture in Landscape Design}

Based on factors such as geographical location, ethnic culture and historical development, different cities have their own unique regional culture. In the process of garden landscape design, the unique cultural heritage of the city can be integrated to make the garden landscape more pleasing; it can also greatly enhance the humanistic color of the landscape.

\subsection{Consider natural conditions}

The landscape is an important part of the urban greening construction. Therefore, when carrying out landscape design, it is necessary to take the local natural conditions into consideration, including topography, plant growth environment, climate conditions, etc. Ecological environment balance is the basis and premise [4]. Within the allowable range of local natural conditions, it is appropriate to add unique styles of plants or buildings to highlight individual designs.

\subsection{Respect human history}

Each city's historical and cultural imprint can always reveal the local cultural heritage and customs, and it is full of powerful humanity. The garden art has played an important cultural expression role in the contemporary era. It reveals the historical context of the city where it is located and becomes the point of convergence and succession of culture [5]. Therefore, the contemporary landscape design company emphasizes that the landscape design must respect the local humanities and history, conform to people's thoughts and emotions, and use the historical elements to convey new meanings in the process of garden landscape design, so that new reactions will occur and new artistic forces will emerge.

\subsection{Popularization principle}

Under normal circumstances, people can sniff out the local cultural values and local customs through excellent garden landscapes. The landscape of a certain area generally reveals the local cultural philosophy and people's spiritual pursuits. People can often appreciate the humanistic care and regional culture while viewing the garden art landscape. People can feel a sense of belonging under the influence of regional culture [5]. In the landscape design, regional culture can be considered 
as one of the most important materials. People can completely build bridges of communication with excellent garden landscapes and promote harmony between people and nature.

\subsection{The principle of uniqueness}

China is a country with rich regional culture and heavy history. The topography and landforms vary widely from place to place and have their own characteristics. Every place has gradually formed a series of unique cultures in its historical development [6]. The design of garden landscape needs to firmly grasp the characteristic differences in regional culture and apply it reasonably and effectively to the design. Only the unique garden landscape design with ingenuity but without loss of regional cultural characteristics can better express the local feelings, promote local culture, and at the same time capture people's sightlines.

\section{Application of Regional Culture in Landscape Design}

\subsection{Landscape design needs to fully grasp the historical context}

In the landscape design, context is an essential element that cannot be replaced. Designers should fully consider the value of the context, integrate it into the landscape design, give the landscape more important significance, and make it bear a responsibility for the inheritance and promotion of the historical culture [6]. While maintaining the continuation of the historical context of the context, it also fully demonstrates its geographical features. Taking the Suzhou garden as an example, this poetic literary garden has always been praised by people. Its design concept contains many ancient philosophical ideas and aesthetic interests, which fully embodies the "image" of the historical context. For example, the Tang Dynasty prevalent poetry, and more lyrical, freehand as the main tone, so the Suzhou garden during the Tang Dynasty is the transition from the natural landscape garden to freehand landscape. By the end of the Song Dynasty, the monarchs were stupid and incompetent. Many literary ideals chose to live in a secluded living environment, shown as Fig.1.

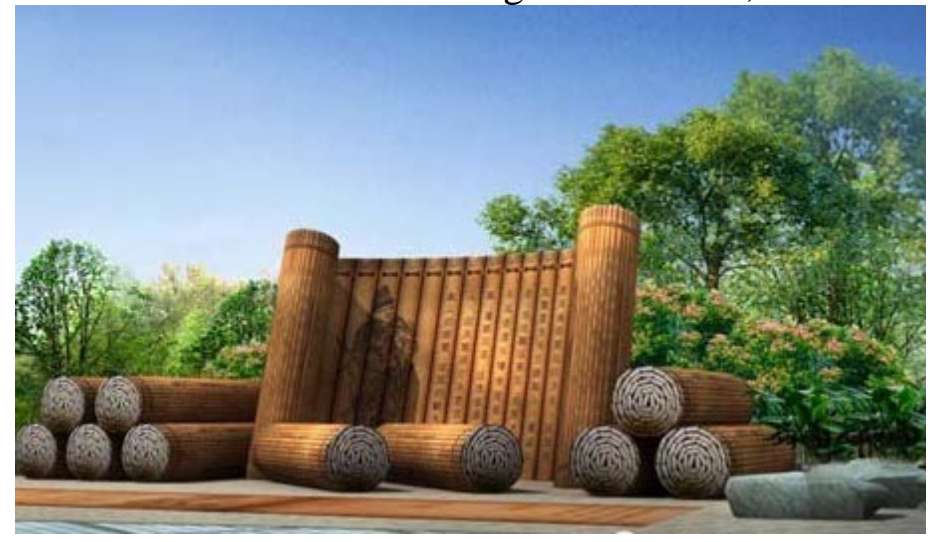

Fig.1 The application of cultural Elements in landscape design

\subsection{Landscape design needs to fully grasp the visual elements}

In the landscape design, visual elements are also very important, which mainly include color, light, material and scale positioning. These elements are indispensable for highlighting the aesthetic value. The garden landscape needs to stimulate people's infinite interest and affection through necessary visual stimuli. Then the viewer can feel the deeper meaning behind the landscape [7]. Among them, the color elements can bring the most direct, violent, and effective visual experience in the landscape visual system, which deserves great attention. However, when the landscape is used for the deployment of colors in the landscape design, it is also necessary for the designer to fully consider the local natural environment and the humanistic environment so as to match the landscape with the most appropriate color, shown as Fig.2. 


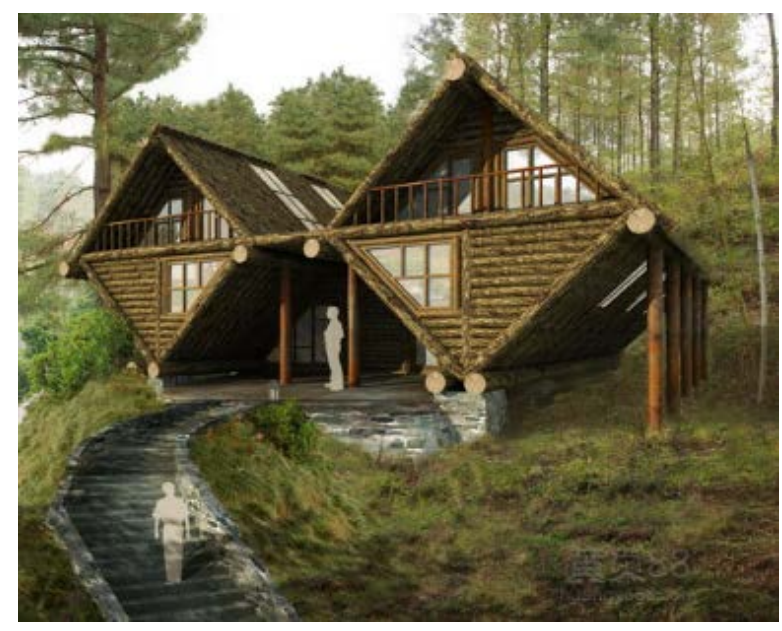

Fig. 2 The application of natural environment in landscape architecture

\subsection{Landscape design needs to fully grasp the social landscape}

When observing the social landscapes everywhere, you will find that there are many complicated and humanized ideas. Garden landscape can reveal regional culture, but it cannot exist in isolation, but it must cooperate with the social landscape to jointly map the city culture. The social landscape is constantly changing with the pace of the times. It also serves as a carrier of regional culture and the social landscape continues to witness the evolution of history [7]. Based on the great role of social landscape in the city, the landscape design should be in harmony with each other, making full use of the local characteristics of materials and crafts and other resources to build a cultural landscape, so that the built landscape is closer to the local people's aesthetic interests, it is shown as Fig.3.

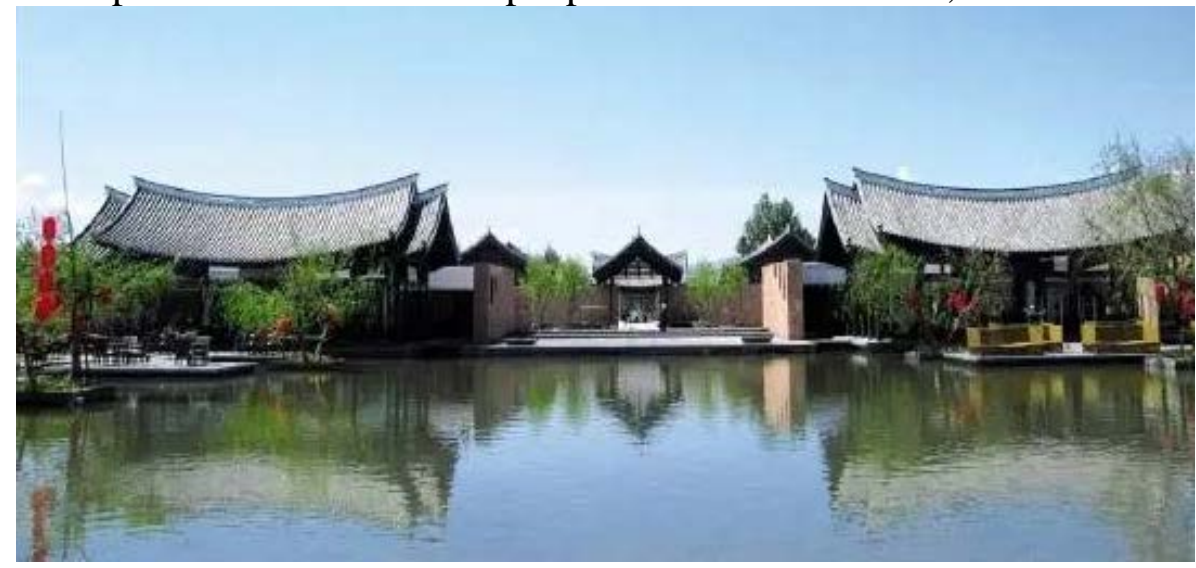

Fig.3 Application of Regional Construction Style in Landscape Design

\section{Summary}

Since the development and current situation of different regions are different, the design and construction of garden landscapes should fully draw on the advanced experience in relevant fields at home and abroad, and according to their own development needs, they should sum up practical and reasonable regional cultural expression methods. Create a distinctive and harmonious landscape environment.

\section{Acknowledgement}

This study was sponsored by the Youth Foundation of Education Department of Sichuan Province, China (grant no. 16ZB0041) and the Social Science Research Base Foundation of Education Department of Sichuan Province, China (grant no. JGYQ2015011). 


\section{References}

[1] Y.Q. Li, Creation of Regional Landscape in New Rural Construction, Journal of Southwest Agricultural University, 2009, vol.7, pp.86-89.

[2] X.R. Wang, Regional Characteristics and Landscape Forms, Chinese Landscape Architecture, 2005, vol.6, pp.16- 24.

[3] Y.F. Yang, Regional Landscape Architecture Design, Journal of Southwest China Normal University, 2009, vol.3, pp.171- 176.

[4] J.X. Zhang, History of Western Urban Planning Thought, Nanjing: Southeast University Press, 2005, pp. 32-35.

[5] Zh.Ch. Li, Building the Central Line of the City, Fujian Architecture, 2009, vol.7, pp.12- 14.

[6] Y.T. Chuan, City Garden Culture, Hefei: Anhui Science and Technology Press, 2012, vol.6, pp.45-47.

[7] L.P. Li, Creating Regional Features of Urban Architecture, Journal of Southwest Agricultural University, 2008, vol.6, pp.1- 4. 